Article

\title{
Emissivity Characteristics of Hydrocarbon Flame and Temperature Measurement by Color Image Processing
}

\author{
Junyi Lin ${ }^{1}$, Xiangyu Zhang ${ }^{2}{ }^{\mathbb{C}}$, Kaiyun Liu ${ }^{1}$ and Wenjie Zhang ${ }^{1, *}$ \\ 1 College of humanities, Xiamen University, Xiamen 361005, China; Linjy@163.com (J.L.); \\ Liukaiyun@stu.xmu.edu.cn (K.L.) \\ 2 Xi'an Thermal Power Research Institute Co., Ltd, Xi'an 710032, China; zhangxiangyu214@163.com \\ * Correspondence: zhangwenjie@xmu.edu.cn; Tel.: + 86-0592-2182-472
}

Received: 8 May 2019; Accepted: 5 June 2019; Published: 7 June 2019

\begin{abstract}
Non-gray radiation should be considered in the temperature and emissivity measurements of hydrocarbon flames. In this paper an improved ratio pyrometry by spectral analysis and color image processing is proposed. A Newton-type iterative method is utilized to analyze the spectrometer signals for the detection of monochromatic emissivity, and then the ratio pyrometry based on color image processing is corrected by the detected monochromatic emissivity without making approximations of the filter profiles of CCD camera. The experiments were conducted on a tubular heating furnace with coal gas and a propane flame. The spectral and spatial distributions of emissivity of hydrocarbon flame were detected, and the temperature measurement results at four conditions coincided with the thermocouple with relative errors less than $8.34 \%$. The soot volume fractions in the turbulent diffusion hydrocarbon flame were approximately estimated from the detected emissivity, and are influenced by the $\mathrm{O} / \mathrm{C}$ in the combustion. This study will provide a simple and effective method for the detection of non-gray radiation of hydrocarbon flames in the combustion industry.
\end{abstract}

Keywords: hydrocarbon flame; temperature; emissivity; spectral analysis; color image processing

\section{Introduction}

The temperature and radiative properties are the important data for combustion process [1]. The combustion products involved in the radiation of hydrocarbon flame are mainly composed of triatomic gases and solid particles, such as carbon dioxide, water vapor and soot [2]. The radiative properties of triatomic gases show a strong spectral selectivity, and the radiation characteristics of soot particles are closely related to the temperature, wavelength and concentration [3]. Therefore, the accurate measurement of temperature and radiative properties of hydrocarbon flame needs to be further researched.

The radiation thermometry based on color image processing has proven to be effective for flame temperature measurement, and the usage of CCD camera to capture flame images is attractive from the perspective of cost reduction [4]. Kuhn et al. evaluated the flame image temperature by two color ratio pyrometry using a lookup table approach without making approximations of the filter profiles [5]. Huang et al. have calculated the distribution of temperature and soot volume of oil swirling flame from CCD images by using a new discrete reconstruction model [6]. Lou et al. used two color CCD cameras to investigate the simultaneous measurement of temperature distribution and radiative properties by radiation analysis [7].

A CCD camera with band response is not suitable for the detection of non-gray radiation due to the loss of detailed spectral information. Therefore, the flame radiation in the previous ratio pyrometry applications was assumed to be gray [8]. Zhang et al. simultaneously reconstructed the inhomogeneous temperature and radiative properties in an arch-fired boiler by radiation image 
processing, and the gas and particle mixture media in the boiler was assumed to be gray emitting [9]. Cheng et al. have reconstructed the temperature and radiative properties in a tube furnace from two different monochromatic radiation intensities, with neglecting the non-gray radiation of gas in visible spectrum [10]. However, the radiation of hydrocarbon flame has a strong spectral selectivity, which requires that the detection device must have a higher spectral resolution [11].

The spectrometer was widely used to detect the radiation spectrum of different flames, and the flame temperature and emissivity were obtained by spectral analysis [12]. Sun et al. proposed a method for judging the gray property of flames based on spectral analysis [13]. Fu et al. [14] proposed the universal function of spectral emissivity in narrow bands, and measured the flame temperature based on spectral bands. Snelling et al. [15] developed a multi-wavelength flame emission technique, and detected the soot temperature and volume fraction in the axisymmetric laminar diffusion flame by collecting the horizontal scans of line-integrated spectra over (500-945) nm. Yan et al. [16] measured the flame temperature and emissivity in the municipal solid waste combustion by spectral analysis and color image processing in the visible spectrum. The spectrometer has a higher spectral resolution and the CCD camera has a higher spatial resolution, thus the combination of color image processing and spectral analysis is effective for the detection of non-gray radiation of hydrocarbon flame.

In this work, the emissivity characteristics of coal gas and propane flame in a tubular heating furnace were detected by spectrometer firstly, and then the two dimensional flame image temperature and emissivity were measured by color image processing, at last the radiation characteristics of combustion products were discussed and some concluding remarks were given.

\section{Emissivity Characteristics and Temperature Measurement}

\subsection{Methodology}

For wavelength range from (300 to 2000) nm and temperature range from (800-2000) K, the Planck's law can be replaced by the Wien's law, as shown in Equation (1):

$$
I(\lambda, T)=\frac{1}{\pi} \varepsilon_{\lambda} \frac{C_{1}}{\lambda^{5}} \cdot \exp \left(-\frac{C_{2}}{\lambda T}\right)
$$

where $I(\lambda, T)$ denotes the monochromatic radiation intensity at wavelength $\lambda$ and temperature $T$, $\mathrm{W} \cdot \mathrm{m}^{-3} \cdot \mathrm{sr}^{-1} . \varepsilon_{\lambda}$ denotes the monochromatic emissivity. $C_{1}$ is the first Planck's constant, $3.742 \times$ $10^{-16} \mathrm{~W} \cdot \mathrm{m}^{2} . \mathrm{C}_{2}$ is the second Planck's constant, $1.4388 \times 10^{-2} \mathrm{~W} \cdot \mathrm{K}$.

According to the Taylor series, the monochromatic emissivity is generally simplified as a function of wavelength [17]:

$$
\varepsilon_{\lambda}=a_{0}+a_{1} \lambda+\cdots+a_{m} \lambda^{m}
$$

where $a_{0}, a_{1}, \cdots, a_{m}$ represent the unknown polynomial coefficients, and $m$ is the polynomial order. The Equation (1) can be rewritten as below:

$$
I(\lambda, T)=\frac{1}{\pi}\left(a_{0}+a_{1} \lambda+\cdots+a_{m} \lambda^{m}\right) \cdot \frac{C_{1}}{\lambda^{5}} \cdot \exp \left(-\frac{C_{2}}{\lambda T}\right)
$$

In the spectrometer, the continuous spectral distribution of radiation intensity is detected, and the unknowns to be solved are the temperature and the emissivity varying with wavelengths. In such conditions, the question becomes how to solve the temperature and polynomial coefficients from the detected radiation intensities $I_{S}(\lambda, T)$. The equations can be expressed as below:

$$
I_{s}\left(\lambda_{i}, T\right)-\frac{1}{\pi}\left(a_{0}+a_{1} \lambda_{i}+\cdots+a_{m} \lambda_{i}^{m}\right) \cdot \frac{C_{1}}{\lambda_{i}^{5}} \cdot \exp \left(-\frac{C_{2}}{\lambda_{i} T}\right)=0 \quad i=1,2, \cdots p
$$

A Newton-type iterative method is utilized to solve the non-linear Equation (4). Firstly the initial value of polynomial order is given and the temperature is iterated to make the residual error 
minimum, as shown in Equation (5). Secondly, the polynomial order is updated and the corresponding temperature and residual error are calculated. Finally the solutions will reach convergence when the polynomial order is increased, and the convergence can be judged by the residual error [18]:

$$
R_{S}=\frac{\left\|\boldsymbol{I}_{S}(\lambda, T)-\left(a_{0}+a_{1} \lambda+\cdots+a_{m} \lambda^{m}\right) \cdot C_{1} \lambda^{-5} / \pi \cdot \exp \left(-C_{2} /(\lambda \boldsymbol{T})\right)\right\|_{L 2}}{\overline{\boldsymbol{I}_{S}(\lambda, T)}}
$$

where $R_{S}$ denotes the residual error. $L 2$ is the two-norm of the matrix. $\overline{I_{S}(\lambda, T)}$ represents the average value of detected radiation intensities, $\mathrm{W} \cdot \mathrm{m}^{-3} \cdot \mathrm{sr}^{-1}$.

In the CCD camera, the radiation is collected in two spectral bands with significant width, and the weighted summation of Planck function is corresponded to the spectral colors of flame image, as shown in Equation (6):

$$
\begin{aligned}
& \int_{\lambda_{1}}^{\lambda_{2}} \eta_{r}(\lambda) \cdot I(\lambda, T) d \lambda=k_{r} \cdot R \\
& \int_{\lambda_{1}}^{\lambda_{2}} \eta_{g}(\lambda) \cdot I(\lambda, T) d \lambda=k_{g} \cdot G
\end{aligned}
$$

where $\lambda_{1}$ and $\lambda_{2}$ are the wavelength response range of CCD camera, m. $\eta_{r}$ and $\eta_{g}$ are the spectral response coefficients for each filter, which can be determined by the filter profiles of CCD camera. $k_{r}$ and $k_{g}$ are the calibration coefficients for radiation intensities of each filter. $R$ and $G$ denote the two spectral colors.

In conventional applications of ratio pyrometry, the radiation intensities received by CCD were simplified to the mean multipliers of finite filter widths and intensities at the central wavelengths of each filter [19], and the temperature could be solved from an explicit equation. However, as shown in the filter profiles of CCD camera, the radiation is collected in three spectral bands with significant width and highly non-uniform spectral response, and the Planck function varies significantly within each spectral window, thus, the simplification of single mean wavelength filter may not accurate for the color image processing. Alternatively, in this work the signal ratio is directly derived from Equation (6) without making approximations of the filter profiles, as Equation (7):

$$
\frac{\int_{\lambda_{1}}^{\lambda_{2}} \eta_{r}(\lambda) \cdot \varepsilon_{\lambda} C_{1} \lambda^{-5} \exp \left(-C_{2} / \lambda T\right) d \lambda}{\int_{\lambda_{1}}^{\lambda_{2}} \eta_{g}(\lambda) \cdot \varepsilon_{\lambda} C_{1} \lambda^{-5} \exp \left(-C_{2} / \lambda T\right) d \lambda}=\frac{k_{r}}{k_{g}} \cdot \frac{R}{G}
$$

The monochromatic emissivity in the equation is corrected by the detected values of spectrometer, and then the temperature can be iterated from the implicit equation above. The flame image emissivity can be calculated from Equation (8), and it indicates the Planck-mean value in the visible spectral bands:

$$
\overline{\varepsilon_{\lambda}}=\frac{k_{r} \cdot R}{\int_{\lambda_{1}}^{\lambda_{2}} \eta_{r}(\lambda) \cdot C_{1} \lambda^{-5} \exp \left(-C_{2} / \lambda T\right) d \lambda}
$$

In summary, the procedure of color image processing and spectral analysis in the present study is outlined below:

1. The characteristic profiles of spectrometer and the filter profiles of CCD camera are calibrated, in order to extract the radiation intensities from the distorted detection signals;

2. The approximate polynomial of monochromatic emissivity is detected from the spectrometer signals by a Newton-type iterative method; and

3. The ratio pyrometry by color image processing is corrected by the monochromatic emissivity, and then the temperature is solved from an implicit equation without making approximations of the filter profiles of CCD camera. 


\subsection{Experimental Results and Discussion}

The experiments were conducted on a gas-fired tubular heating furnace, as shown in Figure 1. The furnace height was $5.46 \mathrm{~m}$ and the cross-section was $3.3 \mathrm{~m} \times 2.7 \mathrm{~m}$. The burner was installed at the center of the bottom wall, with heating capability $1.16 \mathrm{MW}$ and circular nozzle diameter $0.5 \mathrm{~m}$. The propane was added into the coal gas in order to obtain different calorific values and components of gas as real operation. The CCD camera was mounted at the side wall and the probe of the spectrometer was fixed near the fire hole. The detected images and radiation spectrum of the flame were inputted into the computer and were processed for temperature measurement. A movable thermocouple was pushed into the $\operatorname{root}$ (point A), the middle (point B) and the upper (point C) part of flame, respectively, to confirm the flame temperature distribution. As the diameter of K-type thermocouple is far smaller than the flame nozzle, the inserting of the thermocouple has no influence on the temperature distribution of the flame.

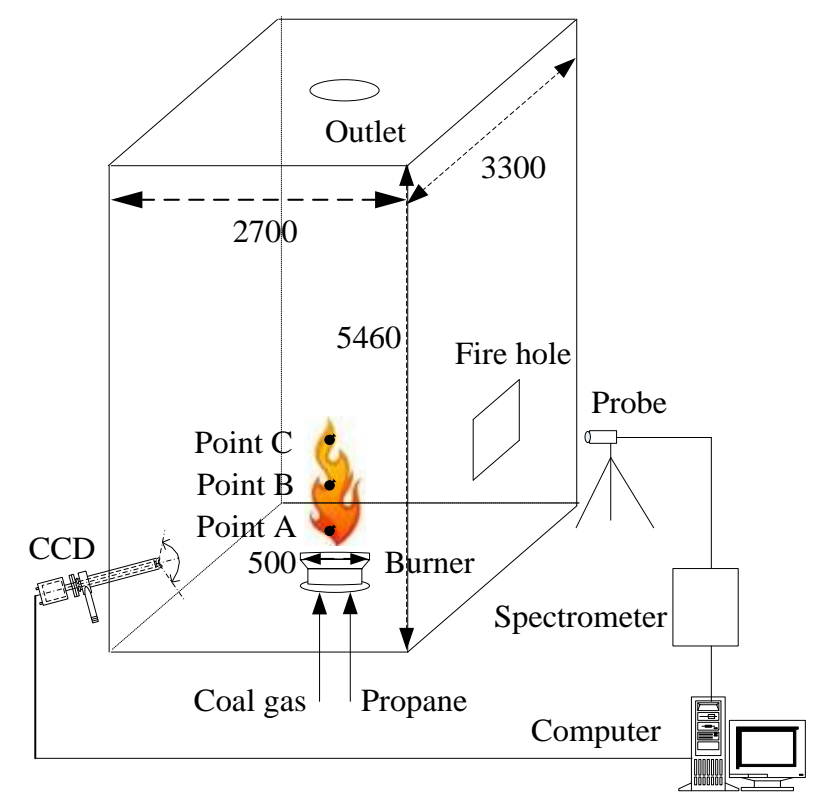

Figure 1. Schematic of the experiment system.

The spectrometer used in the experiment was AvaSpec-2048 (Avantes Inc., Netherlands), which has a choice of 16 different gratings with different dispersion and blaze angles. The response range is in the wavelength from $(1400-2100) \mathrm{nm}$. The spectral resolution is $(0.4-0.6) \mathrm{nm}$, and the signal-to-noise ratio is $250 \mathrm{~dB}$. The calibration was conducted on a blackbody furnace, and the calibration coefficients are determined by the ratios of the detected signals of spectrometer and the monochromatic radiation intensities of blackbody furnace. The characteristic profiles of spectrometer are shown in Figure 2. As shown in the figure, the coefficient curves at three different temperatures are basically in coincidence, indicating that the calibration coefficients are independent of temperature. 


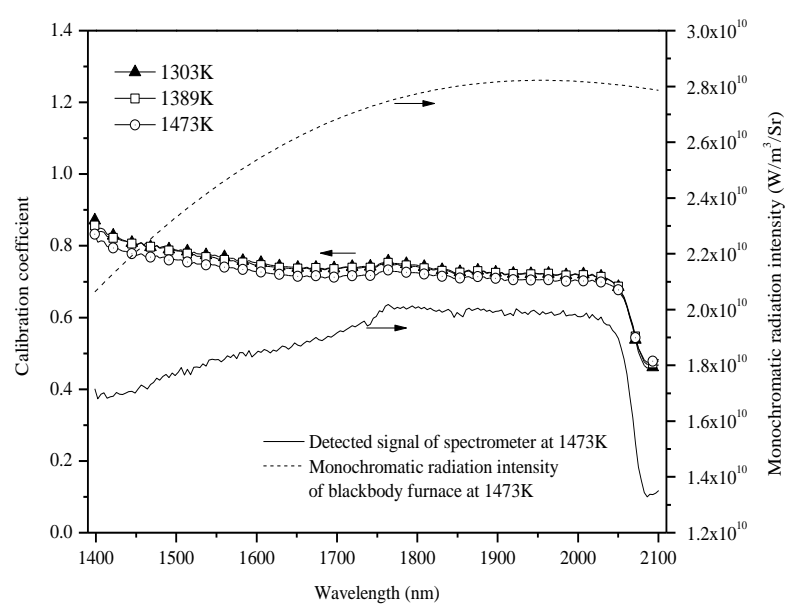

Figure 2. Characteristic calibration for the spectrometer.

The flame image detector consists of a lens, an image guide, a cooling protective sleeve and a Samsung SCC-2313p CCD camera (Samsung Electronics Inc., Suwon, Korea) with 0.4 million pixels $(795 \times 596)$. The signal-to-noise ratio of the CCD camera is $52 \mathrm{~dB}$, and the shutter speed is adjustable from $(1 / 120$ to $1 / 10,000) \mathrm{s}$. The all image enhancement options are set to none. Figure 3 shows the measured filter profiles of the CCD camera, and the radiation is collected in three spectral bands with significant width from $(380-780) \mathrm{nm}$. The red, green and blue channels show similar characteristics with shapes not accurately represented by single Gaussian curves. The coefficients $\eta_{r}$ and $\eta_{g}$ can be obtained from the relative spectral response coefficients of red and green channels in the figure.

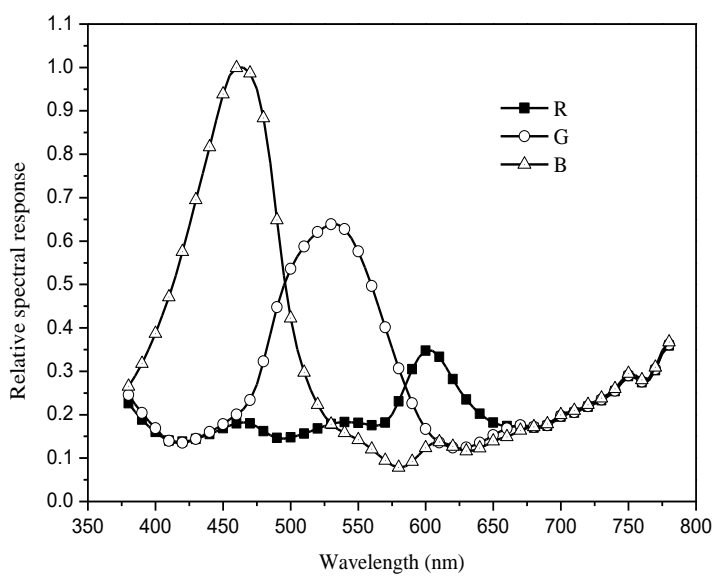

Figure 3. Filter profiles of the CCD camera.

The characteristic profiles of CCD camera were calibrated on a Mikron Model M330 blackbody furnace (LumaSense Technologies, Inc., Santa Clara, CA, USA). The temperature range of blackbody furnace is from ( 500 to 2000$) \mathrm{K}$, and the temperature error is within $\pm 1 \mathrm{~K}$. The two calibration coefficients $k_{r}$ and $k_{g}$ for radiation intensities were calculated by fitting polynomial, as shown in Figure 4.

In order to determine the calibration errors of spectrometer and CCD camera, the temperature and emissivity calculated according to the calibration data were compared with the known values of blackbody furnace, as shown in Table 1. For the blackbody radiation, the spectrometer signals were processed by the conventional ratio pyrometry, and the average temperature and emissivity were calculated, as presented in columns 3 and 5.The maximum calibration errors of temperature and emissivity for the spectrometer are within $2.78 \%$ and $5.43 \%$, while those are within $1.31 \%$ and $6.72 \%$ for the CCD camera, respectively. 


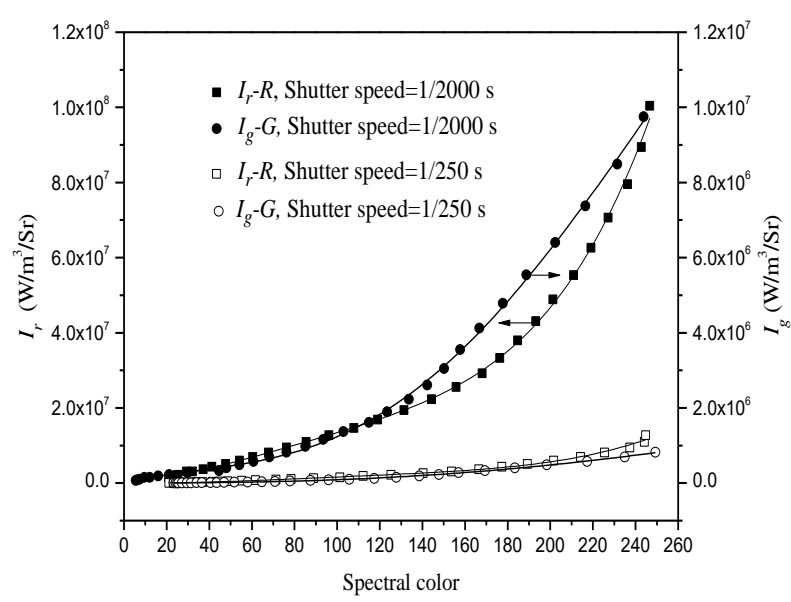

Figure 4. Characteristic calibration for the CCD camera.

Table 1. Calibration errors of spectrometer and CCD camera.

\begin{tabular}{cccccccccc}
\hline \multicolumn{3}{c}{ Blackbody Furnace } & \multicolumn{4}{c}{ Spectrometer } & \multicolumn{4}{c}{ CCD Camera } \\
\hline $\boldsymbol{T}(\mathbf{K})$ & $\boldsymbol{\varepsilon}$ & $\boldsymbol{T} \mathbf{( K )}$ & Error $\mathbf{( \% )}$ & $\boldsymbol{\varepsilon}$ & Error $\mathbf{( \% )}$ & $\boldsymbol{T ( K )}$ & Error $\mathbf{( \% )}$ & $\boldsymbol{\varepsilon}$ & Error $\mathbf{( \% )}$ \\
\hline 1143 & 1.0 & 1116.1 & 2.35 & 1.05 & 4.71 & 1144.6 & 0.14 & 0.97 & 2.53 \\
1173 & 1.0 & 1140.4 & 2.78 & 1.05 & 5.43 & 1162.9 & 0.87 & 1.05 & 5.25 \\
1203 & 1.0 & 1178.3 & 2.05 & 1.04 & 4.33 & 1209.1 & 0.51 & 0.96 & 3.94 \\
1233 & 1.0 & 1219.2 & 1.12 & 1.03 & 2.78 & 1246.4 & 1.08 & 0.96 & 4.03 \\
1263 & 1.0 & 1281.2 & 1.44 & 0.97 & 2.57 & 1279.7 & 1.31 & 0.93 & 6.72 \\
1293 & 1.0 & 1308.1 & 1.17 & 0.98 & 2.24 & 1307 & 1.07 & 0.95 & 5.06 \\
1323 & 1.0 & 1335.3 & 0.93 & 0.98 & 2.02 & 1339.1 & 1.22 & 0.96 & 3.67 \\
1353 & 1.0 & 1362.3 & 0.69 & 0.99 & 1.14 & 1364.3 & 0.84 & 0.97 & 3.18 \\
1383 & 1.0 & 1390.0 & 0.50 & 0.99 & 1.02 & 1386.7 & 0.26 & 0.98 & 1.93 \\
1413 & 1.0 & 1425.2 & 0.86 & 0.98 & 1.93 & 1410.2 & 0.21 & 1.02 & 1.72 \\
\hline
\end{tabular}

The components of coal gas are listed as below: $47.7 \% \mathrm{H}_{2}, 28.9 \% \mathrm{CH}_{4}, 3 \% \mathrm{CO}_{2}, 19.2 \% \mathrm{CO}$, and $0.2 \% \mathrm{O}_{2}$. The calorie of coal gas and propane was 4400 and $21,742 \mathrm{kcal} / \mathrm{m}^{3}$, respectively. The propane and coal gas flows were adjusted to obtain different capacities of the burner as real operation, and the propane flow was gradually increased from case 1 to 4 .The preheated combustion air was injected into the furnace independently to form a diffusion flame with the fuel, and the air volume was adjusted according to the oxygen content of flue gas. Assuming that the fuel is completely combusted, the flue gas compositions at four conditions can be estimated, as shown in Table 2.

Table 2. Experimental conditions for four cases.

\begin{tabular}{cccccc}
\hline Case & $\begin{array}{c}\text { Propane } \\
\left(\mathbf{m}^{\mathbf{3}} \mathbf{h}\right)\end{array}$ & $\begin{array}{c}\text { Coal Gas } \\
\left(\mathbf{m}^{\mathbf{3}} \mathbf{h}\right)\end{array}$ & $\begin{array}{c}\text { Capacity of the } \\
\text { Burner } \mathbf{( \% )}\end{array}$ & $\begin{array}{c}\text { Oxygen } \\
\text { Content } \mathbf{( \% )}\end{array}$ & Components of Flue Gas \\
\hline 1 & 0 & 113.6 & 50 & 3.92 & $8.9 \% \mathrm{CO}_{2}+18.4 \% \mathrm{H}_{2} \mathrm{O}+69.7 \% \mathrm{~N}_{2}$ \\
2 & 7.92 & 71.32 & 50 & 3.99 & $8.8 \% \mathrm{CO}_{2}+15.6 \% \mathrm{H}_{2} \mathrm{O}+71.5 \% \mathrm{~N}_{2}$ \\
3 & 11.88 & 106.98 & 75 & 3.64 & $9.0 \% \mathrm{CO}_{2}+15.9 \% \mathrm{H}_{2} \mathrm{O}+71.3 \% \mathrm{~N}_{2}$ \\
4 & 22.21 & 51.82 & 75 & 2.69 & $9.8 \% \mathrm{CO}_{2}+15.2 \% \mathrm{H}_{2} \mathrm{O}+72.2 \% \mathrm{~N}_{2}$ \\
\hline
\end{tabular}

Figure 5 shows the detected spectrometer signals under four cases. Taking into account the pulsation of the turbulent diffusion flame, the average values of the spectrometer signals within five minutes were calculated. The sampling period of spectrometer is $30 \mathrm{~s}$. As the signal noise is large at wavelengths close to $1400 \mathrm{~nm}$ and $2100 \mathrm{~nm}$, only the monochromatic radiation intensities from (1500 to 2000) $\mathrm{nm}$ were corrected from the spectrometer signals. 


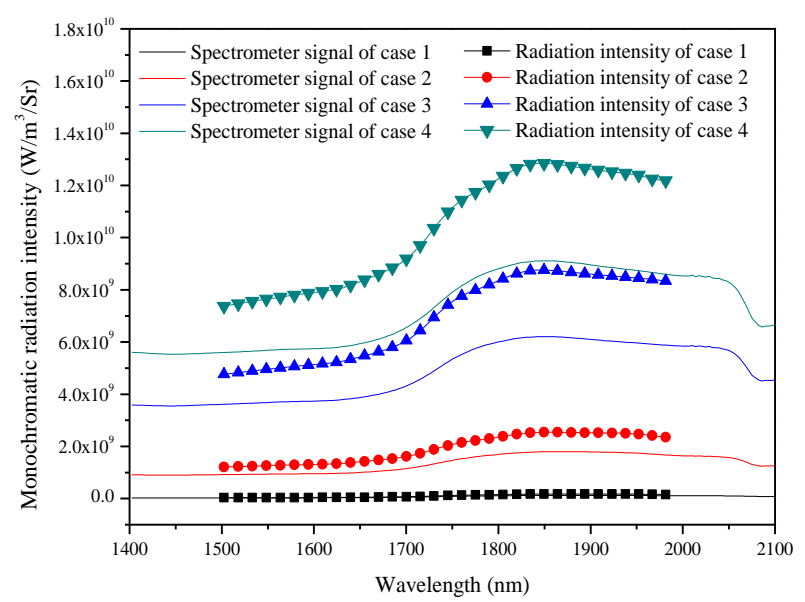

Figure 5. Time-averaged spectrometer signals of four cases.

The variations of temperature and residual error with polynomial order at four conditions are shown in Figure 6. With the increase of polynomial order, the residual errors decrease firstly and then stabilize. When the polynomial order is greater than six, the changes of temperature and residual error are very small, indicating that the Newton-type iterative method is considered to be converged. Therefore the polynomial order for monochromatic emissivity is selected to be six, and the flame temperatures of four cases are confirmed to be $1195.5 \mathrm{~K}, 1343 \mathrm{~K}, 1461.4 \mathrm{~K}$, and $1497.7 \mathrm{~K}$, respectively.

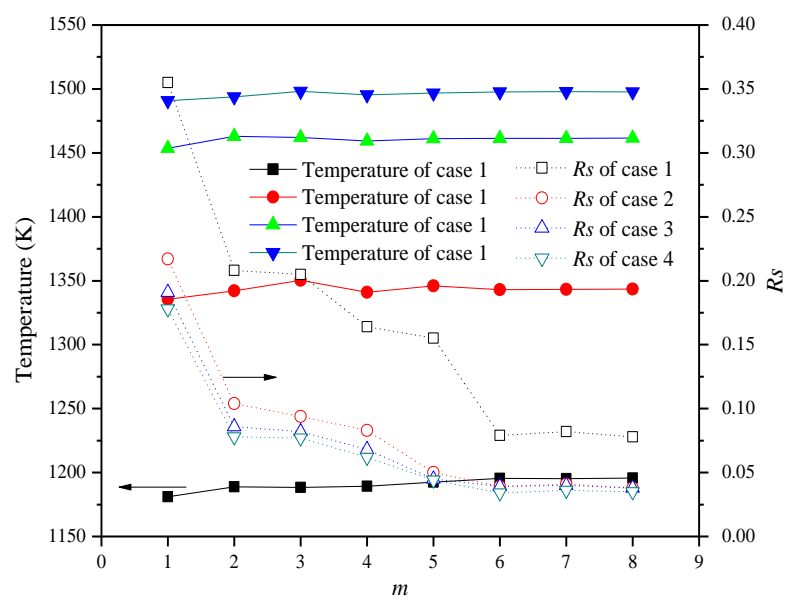

Figure 6. The flame temperatures of four cases detected by spectrometer.

The spectral distribution of emissivity of coal gas and propane flame under four experimental conditions were calculated according to the six-order polynomial of wavelength, as shown in Figure 7. The monochromatic emissivity varies with wavelength and shows a similar trend of variation at four conditions, indicating the strong spectral selectivity of the radiation of hydrocarbon flame. 


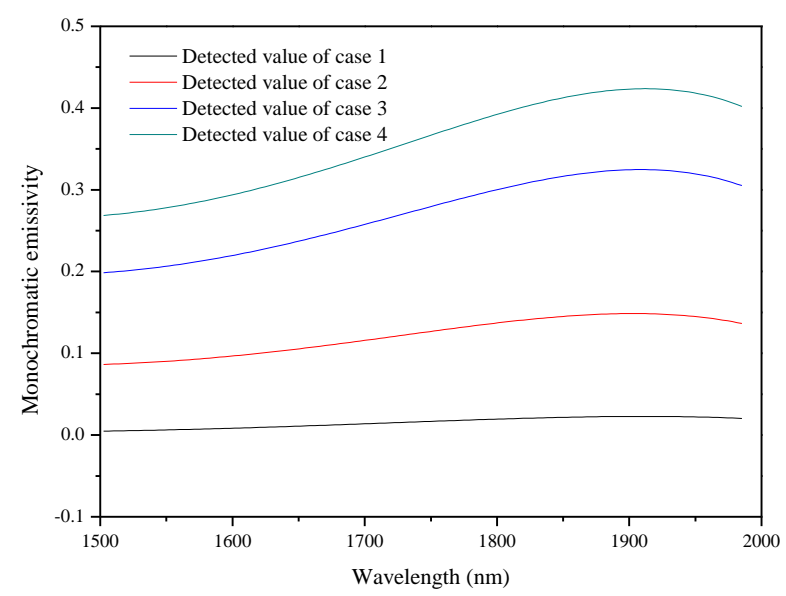

Figure 7. The detected monochromatic emissivity of four cases.

The radiation intensities were reconstructed from the detected temperature and monochromatic emissivity, and the results were compared with the spectrometer signals, as shown in Figure 8 . The reconstructed radiation intensities of four cases agree well with the detected values, proving the performance of the proposed method on spectral analysis.

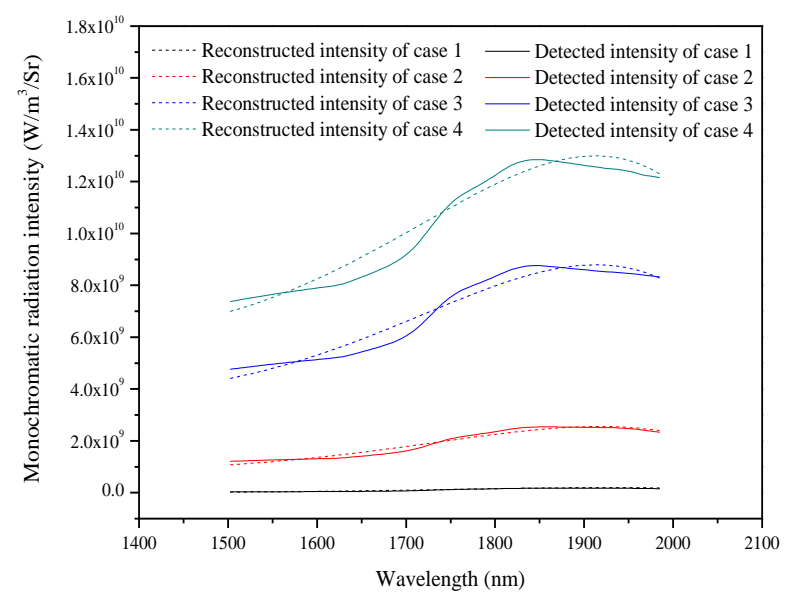

Figure 8. Comparisons of the detected and reconstructed monochromatic radiation intensities.

Figure 9 shows the flame images of four cases captured by the CCD camera. The shutter speed for case 1 is $1 / 250 \mathrm{~s}$, and the others are 1/2000 s. The sampling number of flame images of each case is 60 frames in $5 \mathrm{~min}$. The spectral colors of each pixel were extracted from the flame images, and the time-averaged values were calculated as the detection signals for the turbulent diffusion flame.

The two dimensional flame image temperatures were calculated by ratio pyrometry with corrections of monochromatic emissivity, and the values in the central axis of flame are presented in Figure 10a. The detected temperatures were verified by a movable thermocouple at three points. The temperature distributions of two results along the height are nearly the same, which is higher in the root than that in the upper part. 

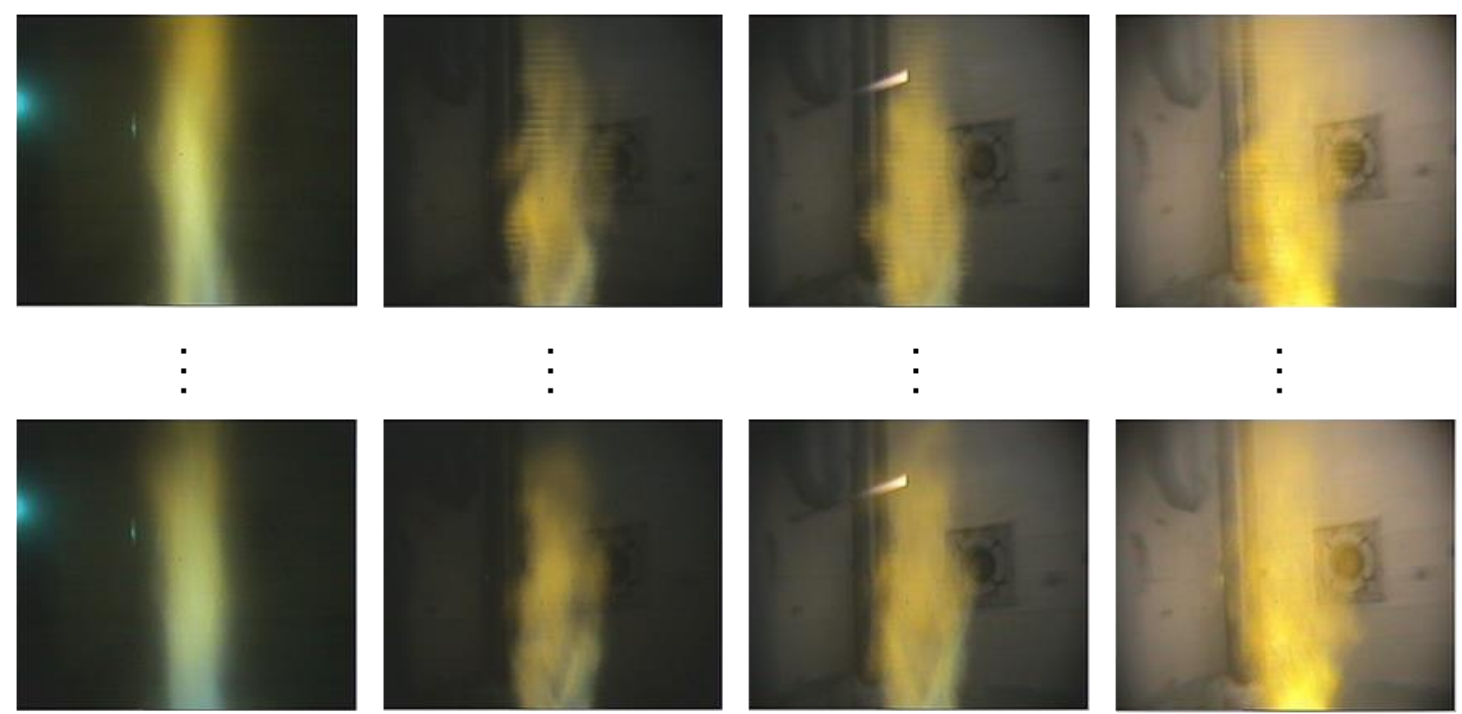

Figure 9. Flame images of four cases (60 frames/5 min).

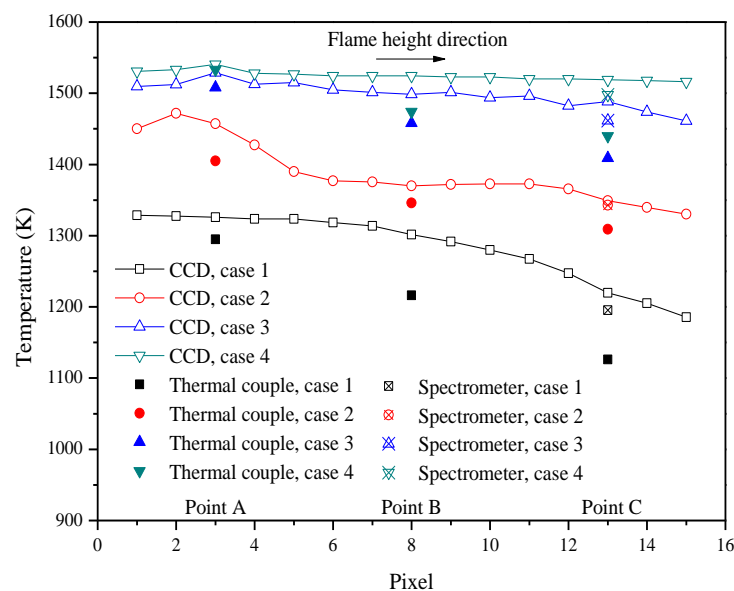

(a)

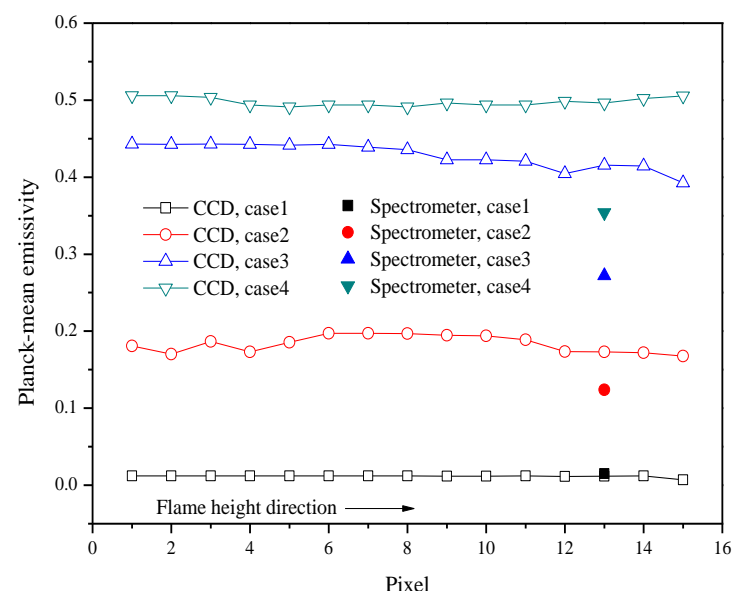

(b)

Figure 10. Measurement results by color image processing. (a) Flame image temperatures in the height direction; and (b) flame image emissivity in the height direction.

The flame image emissivity along the height direction is shown in Figure 10b. Different from the temperature measurement results, the flame image emissivity changes a little along the height direction, and it is evenly distributed for the turbulent diffusion flame. The Planck-mean values of monochromatic emissivity detected by spectrometer were compared with the flame image emissivity, and the deviations demonstrate that the emissivity of hydrocarbon flame in the visible spectral bands is different from that between 1500 and $2000 \mathrm{~nm}$.

The temperatures measured by CCD camera, thermocouple and spectrometer were compared in Table 3. As we can see, the measurement results of spectrometer and CCD camera are close to each other, and are both higher than those of thermocouple. It is attributed to that the temperature obtained by radiation thermometry represents the cumulative value of all radiation in the gaze direction, while it is for the single point inside the flame by thermocouple. The maximum temperature error is within $8.34 \%$, indicating that the color image processing with corrections of monochromatic emissivity is reliable for the temperature detection of hydrocarbon flame. 
Table 3. Comparison of the temperature measurement results.

\begin{tabular}{|c|c|c|c|c|c|c|c|c|c|c|}
\hline \multirow[b]{2}{*}{ Cases } & \multirow[b]{2}{*}{$\begin{array}{l}\text { Spectrometer } \\
\text { (K) }\end{array}$} & \multicolumn{3}{|c|}{ Point A } & \multicolumn{3}{|c|}{ Point B } & \multicolumn{3}{|c|}{ Point C } \\
\hline & & $\begin{array}{l}\text { Thermal } \\
\text { Couple } \\
\text { (K) }\end{array}$ & $\begin{array}{l}\text { CCD } \\
\text { (K) }\end{array}$ & $\begin{array}{l}\text { Error } \\
(\%)\end{array}$ & $\begin{array}{l}\text { Thermal } \\
\text { Couple } \\
\text { (K) }\end{array}$ & $\begin{array}{c}\text { CCD } \\
(\mathrm{K})\end{array}$ & $\begin{array}{c}\text { Error } \\
(\%)\end{array}$ & $\begin{array}{l}\text { Thermal } \\
\text { Couple } \\
\text { (K) }\end{array}$ & $\begin{array}{l}\text { CCD } \\
\text { (K) }\end{array}$ & $\begin{array}{l}\text { Error } \\
(\%)\end{array}$ \\
\hline 1 & 1195.5 & 1295 & 1325.8 & 2.38 & 1216 & 1301.3 & 7.01 & 1126 & 1219.9 & 8.34 \\
\hline 2 & 1343 & 1405 & 1457.3 & 3.72 & 1346 & 1370 & 1.78 & 1309 & 1349.3 & 3.08 \\
\hline 3 & 1461.4 & 1508 & 1528.7 & 1.37 & 1458 & 1498.5 & 2.78 & 1409 & 1488.4 & 5.64 \\
\hline 4 & 1497.7 & 1533 & 1540.5 & 0.49 & 1474 & 1524.3 & 3.41 & 1440 & 1519 & 5.49 \\
\hline
\end{tabular}

\section{Radiation Characteristics of Combustion Products}

The gas and particle mixture media in the gas-fired tubular heating furnace is assumed to be non-gray emitting, absorbing without scattering. The detected values of CCD camera and spectrometer represent the emissivity of all combustion products in the furnace. Assuming that the main products involved in the radiation are $\mathrm{CO}_{2}, \mathrm{H}_{2} \mathrm{O}$ and soot, the monochromatic emissivity of flame is determined by the following equation [20]:

$$
\varepsilon_{\lambda, f}=1-\tau_{\mathrm{CO}_{2}+\mathrm{H}_{2} \mathrm{O}, \lambda} \cdot \tau_{\text {soot }, \lambda}
$$

where $\varepsilon_{\lambda, f}$ denotes the monochromatic emissivity of the combustion products, and it shows a cumulative effect of absorption coefficients in the cross section. $\tau_{\mathrm{CO}_{2}+\mathrm{H}_{2} \mathrm{O}, \lambda}$ denotes the narrowband transmittance of $\mathrm{CO}_{2}$ and $\mathrm{H}_{2} \mathrm{O}$ mixtures, and it can be calculated by the SLG spectral model [21]. The wave number is between 5000 and $26,000 \mathrm{~cm}^{-1}$, and the parameters refer to the measurement results of Luding et al. [22,23]. The partial pressures of $\mathrm{CO}_{2}$ and $\mathrm{H}_{2} \mathrm{Oare}$ calculated based on the flue gas compositions in Table 2. $\tau_{\text {soot }, \lambda}$ denotes the spectral transmittance of soot, determined as follows:

$$
\tau_{\text {soot }, \lambda}=\exp \left(-k_{\text {soot }, \lambda} L\right)
$$

where $L$ is the mean path length of ray, $\mathrm{m}$. It is assumed that the soot is only in the flame area, and the path length of soot radiation is $0.45 \mathrm{~m}$. $k_{\text {soot }, \lambda}$ denotes the spectral absorption coefficient of soot, $\mathrm{m}^{-1}$. According to the Mie's theory of scattering, the spectral absorption coefficient of soot is determined as follows [24]:

$$
k_{\text {soot }, \lambda}=\frac{36 \pi \cdot n \cdot k}{\left(n^{2}-k^{2}+2\right)^{2}+4 n^{2} \cdot k^{2}} \cdot \frac{f_{v}}{\lambda}
$$

where $f_{v}$ is the soot volume fraction in the flame. $n$ and $k$ are the real and imaginary parts of the complex refractive index of soot particles, respectively, and the values can be determined by referring to the results of Chang et al. [25]:

$$
\begin{aligned}
& n=1.811+0.1263 \ln \lambda+0.027 \ln ^{2} \lambda+0.0417 \ln ^{3} \lambda \\
& k=0.5821+0.1213 \ln \lambda+0.2309 \ln ^{2} \lambda-0.01 \ln ^{3} \lambda
\end{aligned}
$$

The monochromatic emissivity of the mixtures of $\mathrm{CO}_{2}, \mathrm{H}_{2} \mathrm{O}$ and soot is shown in Figure 11 . The wavelength range is $1000-2000 \mathrm{~nm}$. The pressure is $100 \mathrm{kPa}$, and the temperature is $1343 \mathrm{~K}$. The volume fractions of soot are set as $0 \mathrm{ppm}$ and $7 \mathrm{ppm}$, respectively. As shown in the figure, with the increasing soot volume fraction, the monochromatic emissivity of combustion products is increased. The soot radiation is continuously in the whole band, and is inversely proportional to the wavelength. The mixed gases of $\mathrm{CO}_{2}$ and $\mathrm{H}_{2} \mathrm{O}$ are not radiated when the wavelength is less than $1500 \mathrm{~nm}$, while it has strong absorption and emission capability between 1500 and $2000 \mathrm{~nm}$. Thus in the wavelength less than $1500 \mathrm{~nm}$, the monochromatic emissivity is dominated by soot radiation and is decreased with the increasing wavelength. In the wavelength from $1500-2000 \mathrm{~nm}$, the monochromatic emissivity is affected by both gas emission and soot radiation. 


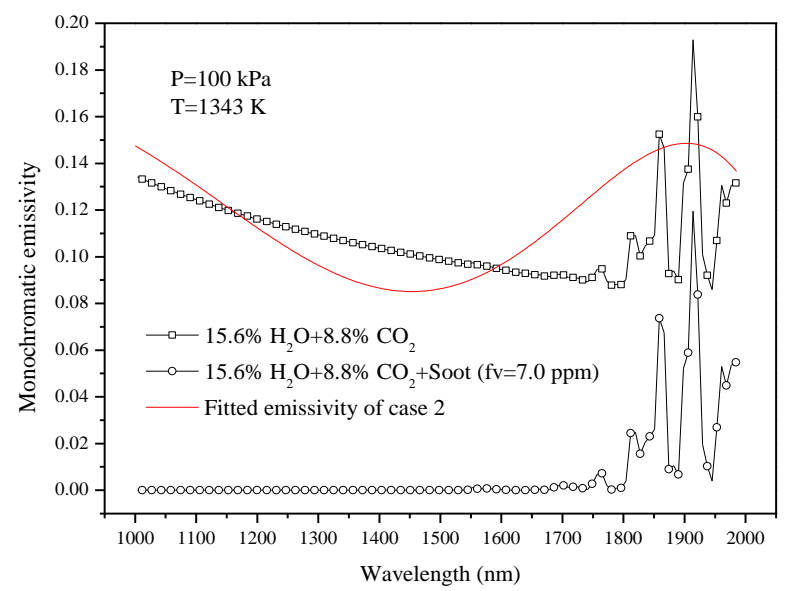

Figure 11. The monochromatic emissivity of the mixtures of $\mathrm{CO}_{2}, \mathrm{H}_{2} \mathrm{O}$, and soot.

The monochromatic emissivity of combustion products is only related to the volume fraction of soot when the gas compositions and temperature are known. Therefore, the soot volume fraction can be approximately estimated from the detected monochromatic emissivity by spectrometer, and the principle is to find the solution making the following equation minimum:

$$
f_{v} \approx \min \left\|\varepsilon_{\lambda}-\varepsilon_{\lambda, f}\right\|_{L 2}
$$

where $\varepsilon_{\lambda}$ denotes the fitted monochromatic emissivity calculated by the six-order polynomial of wavelength, and $\varepsilon_{\lambda, f}$ denotes the calculated monochromatic emissivity of combustion products. $L 2$ is the two-norm of the matrix.

According to the equations above, the soot volume fractions at four conditions were estimated to be $0.5,7,17$, and $24 \mathrm{ppm}$ respectively. Figure 12 shows the comparisons of the monochromatic emissivity between the detected values of spectrometer and the calculated values of combustion products. As we can see, the two curves of each case are only mathematically approximated, indicating that the actual flame radiation is much more complicated than the theoretical case.

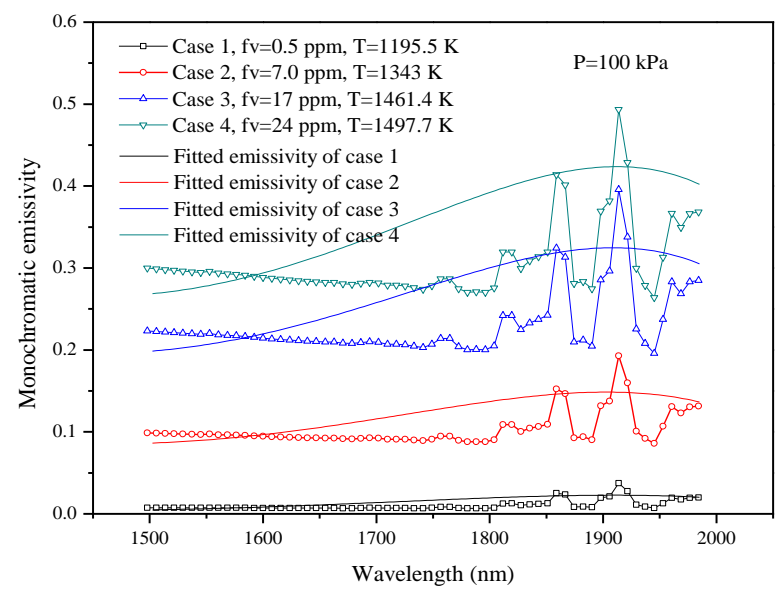

Figure 12. Reconstruction of soot volume fractions of four cases by monochromatic emissivity.

As we know, the soot in the hydrocarbon flame is generated by a series of dehydrogenation polymerizations, and it is influenced by the ratios of oxygen to carbon [26]. As shown in Figure 13, the ratios of oxygen to carbon in the combustion are decreased with the increasing propane fuel from case 1 to case 4 , and then the soot volume fractions in the anoxic region are increased. 


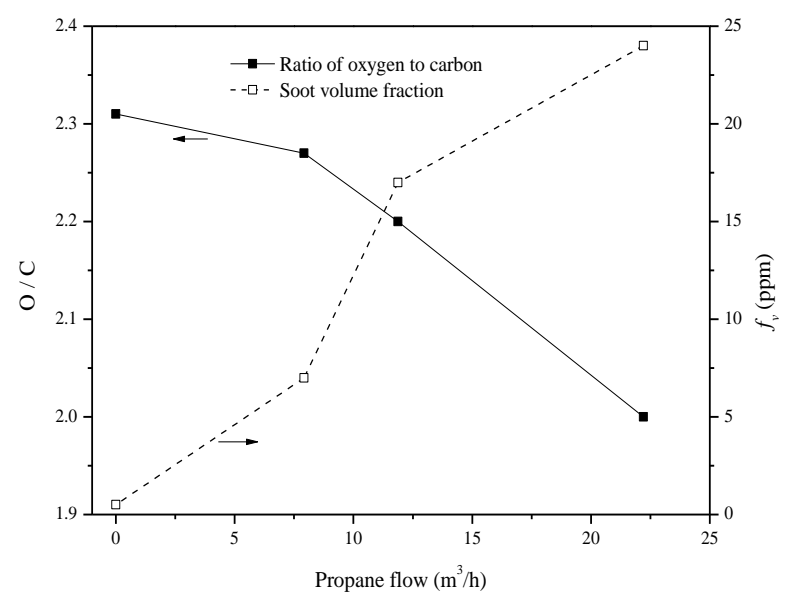

Figure 13. The ratios of oxygen to carbon and soot volume fractions of four cases.

Different from the spectrometer, the flame image emissivity detected by CCD camera represents the Planck-mean emissivity in the visible spectral bands, and it is also influenced by the filter profiles of CCD camera. Based on the detected flame image temperatures and the estimated soot volume fractions, the Planck-mean emissivity of the combustion products can be determined as follows [27]:

$$
\varepsilon_{P}=\frac{\int_{\lambda_{1}}^{\lambda_{2}} \eta_{r}(\lambda) \cdot \varepsilon_{\lambda, f} \cdot C_{1} \lambda^{-5} \exp \left(-C_{2} / \lambda T\right) d \lambda}{\int_{\lambda_{1}}^{\lambda_{2}} \eta_{r}(\lambda) \cdot C_{1} \lambda^{-5} \exp \left(-C_{2} / \lambda T\right) d \lambda}
$$

where $\varepsilon_{P}$ denotes the Planck-mean emissivity of combustion products such as $\mathrm{CO}_{2}, \mathrm{H}_{2} \mathrm{O}$, and soot in the visible spectral bands.

As shown in Figure 14, the flame image emissivity obtained by color image processing essentially agreed with the Planck-mean emissivity of estimated soot volume fraction in the visible spectral bands, indicating that the flame image emissivity detected by CCD camera also can be used to reconstruct the soot volume fraction in the flame. On the other hand, the CCD camera has millions of pixels and has a higher spatial resolution, thus it is feasible for the usage of CCD image processing to detect the spatial distribution of temperature and radiative properties of hydrocarbon flame.

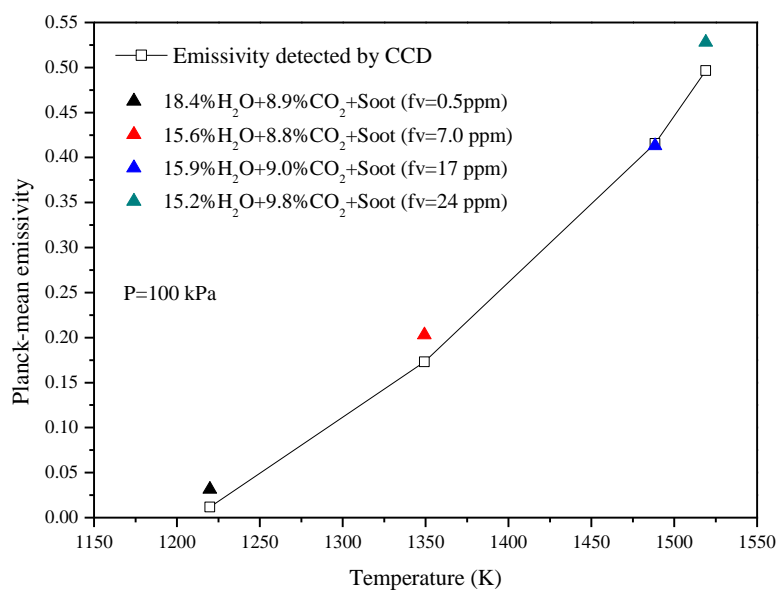

Figure 14. The Planck-mean emissivity of combustion products in the visible spectral bands.

\section{Discussion}

This paper presented an improved ratio pyrometry based on spectral analysis and color image processing, and the temperature and emissivity of coal gas and propane flame in a tubular heating furnace were measured by the presented method. The detected monochromatic emissivity presents 
a six-order polynomial of wavelength, and it is dominated by soot radiation in the visible spectral bands while it is affected by both gas emission and soot radiation in the 1500-2000 $\mathrm{nm}$ bands. The soot volume fractions in the hydrocarbon flame were approximately estimated from the detected emissivity, and are influenced by the $\mathrm{O} / \mathrm{C}$ in the combustion. The two dimensional flame image temperature and emissivity were measured by color image processing with corrections of monochromatic emissivity, and the temperature measurement errors are less than $8.34 \%$, which validate the effectiveness and accuracy for its application in the temperature measurement of hydrocarbon flame. The flame image emissivity represents the Planck-mean emissivity in the visible spectral bands, and it is also closely related to the soot volume fractions. The spatial information of detected temperature and emissivity of hydrocarbon flame will provide important references for studying the soot generation and oxidation processes.

Author Contributions: Methodology: X.Z.; validation: J.L., K.L., and W.Z.; data curation: K.L.; writing-original draft preparation: J.L.; writing editing: W.Z.; funding acquisition: W.Z.

Funding: This research was funded by Ministry of Science and Technology of the People's Republic of China, grant number 2018YFB0604100.

Conflicts of Interest: The authors declare no conflict of interest.

\section{References}

1. Javier, B.; Tatiana, G. Diagnostic techniques for the monitoring and control of practical flames. Prog. Energy Combust. Sci. 2010, 36, 375-411.

2. Liu, F.; Thomson, K.A.; Smallwood, G.J. Soot temperature volume fraction retrieval from spectrally resolved flame emission measurement in laminar axisymmetric coflow diffusion flames: Effect of self-absorption. Combust. Flame 2013, 160, 1693-1705. [CrossRef]

3. Coppalle, A.; Joyeux, D. Temperature and soot volume fraction in turbulent diffusion flames: Measurements of mean and fluctuating values. Combust. Flame 1994, 96, 275-285. [CrossRef]

4. Vattulainen, J.; Nummela, V.; Hernberg, R.; Kytölä, J. A system for quantitative imaging diagnostics and its application to pyrometric in-cylinder flame-temperature measurements in large diesel engines. Meas. Sci. Technol. 2000, 11, 103-119. [CrossRef]

5. Kuhn, P.B.; Ma, B.; Connelly, B.C.; Smooke, M.D.; Long, M.B. Soot and thin-filament pyrometry using a color digital camera. Proc. Combust. Inst. 2011, 33, 743-750. [CrossRef]

6. Huang, Q.X.; Wang, F.; Liu, D.; Ma, Z.Y.; Yan, J.H.; Chi, Y.; Cen, K.F. Reconstruction of soot temperature and volume fraction profiles of an asymmetric flame using stereoscopic tomography. Combust. Flame 2009, 156, 565-573. [CrossRef]

7. Lou, C.; Li, W.H.; Zhou, H.C.; Salinas, C.T. Experimental investigation on simultaneous measurement of temperature distributions and radiative properties in an oil-fired tunnel furnace by radiation analysis. Int. J. Heat Mass Transf. 2011, 54, 1-8. [CrossRef]

8. Keyvan, S.; Rossow, R.; Romero, C.; Li, X.-X. Comparison between Visible and Near-IR Flame Spectra from Natural Gas-FireFurnace for Blackbody Temperature Measurements. Fuel 2004, 83, 1175-1181. [CrossRef]

9. Zhang, X.; Zheng, S.; Zhou, H.; Zhang, B.; Wang, H.; Xu, H. Simultaneously reconstruction of inhomogeneous temperature and radiative properties by radiation image processing. Int. J. Therm. Sci. 2016, 107, 121-130.

10. Cheng, Q.; Zhang, X.Y.; Wang, Z.C.; Zhou, H.; Shao, S. Simultaneous Measurement of Three-Dimensional Temperature Distributions and Radiative Properties Based on Radiation Image Processing Technology in a Gas-fired Pilot Tubular Furnace. Heat Transf. Eng. 2014, 35, 770-779. [CrossRef]

11. Christian, G.P.; Alexander, C.W.; David, M.S.; Donaldson, A.B.; Jonathan, L.H. Aluminum Flame Temperature Measurements in Solid Propellant Combustion. Appl. Spectrosc. 2014, 68, 362-366.

12. Arias, L.; Sbarbaro, D.; Torres, S. Removing baseline flame's spectrum by using advanced recoveringspectrum techniques. Appl. Opt. 2012, 51, 6111-6116. [CrossRef]

13. Sun, Y.; Lou, C.; Zhou, H. A simple judgment method of gray property of flames based on spectral analysis and the two-color method for measurements of temperatures and emissivity. Proc. Combust. Inst. 2011, 33, 735-741. [CrossRef]

14. Fu, T.; Duan, M.; Tang, J.; Shi, C. Measurements of the directional spectral emissivity based on a radiation heating source with alternating spectral distributions. Int. J. Heat Mass Transf. 2015, 90, 1207-1213. [CrossRef] 
15. Snelling, D.R.; Thomson, K.A.; Smallwood, G.J.; G-uacute, L.; Weckman, E.J.; Fraser, R.A. Spectrally Resolved Measurement of Flame Radiation to Determine Soot Temperature and Concentration. AIAA J. 2002, 40, 1789-1795. [CrossRef]

16. Yan, W.; Chen, D.; Yang, Z.; Yan, E.; Zhao, P. Measurement of Soot Volume Fraction and Temperature for Oxygen-Enriched Ethylene Combustion Based on Flame Image Processing. Energies 2017, 10, 750. [CrossRef]

17. Yan, W.; Ya, Y.; Du, F.; Shao, H.; Zhao, P. Spectrometer-Based Line-of-Sight Temperature Measurements during Alkali-Pulverized Coal Combustion in a Power Station Boiler. Energies 2017, 10, 1375. [CrossRef]

18. Liu, H.; Zheng, S.; Zhou, H.; Qi, C. Measurement of distributions of temperature and wavelength-dependent emissivity of a laminar diffusion flame using hyper-spectral imaging technique. Meas. Sci. Technol. 2016, 27, 1-10. [CrossRef]

19. Hossain, M.M.; Lu, G.; Sun, D.; Yan, Y. Three-dimensional reconstruction of flame temperature and emissivity distribution using optical tomographic and two-color pyrometric techniques. Meas. Sci. Technol. 2013, 24, 1-10. [CrossRef]

20. Chu, H.; Liu, F.; Zhou, H. Calculations of gas radiation heat transfer in a two-dimensional rectangular enclosure using the line-by-line approach and the statistical narrow-band correlated-k model. Int. J. Therm. Sci. 2012, 59, 66-74. [CrossRef]

21. Hofgren, H.; Sundén, B. Evaluation of Planck-mean coefficients for particle radiative properties in combustion environments. Heat Mass Transf. 2015, 51, 507-519. [CrossRef]

22. Ludwig, D.B.; Malkmus, W.; Reardon, J.E.; Thomson, J.A.L.; Goulard, R. Handbook of Infrared Radiation from Combustion Gases. NASA SP3080; NASA Marshall Space Flight Center: Huntsville, AL, USA, 1973.

23. Joseph, D.; Perez, P.; Cuenot, B. Discrete Ordinates and Monte Carlo Methods for Radiative Transfer Simulation applied to CFD combustion modeling. J. Heat Transf. 2018, 131. [CrossRef]

24. Shimogori, M.; Yoshizako, H.; Shimogori, Y.; Richardson, M. Characterization of Coal Ash Emissivity in High Temperature Atmospheres. JSME Int. J. Ser. B 2006, 49, 265-270. [CrossRef]

25. Chang, H.; Charalampopoulos, T.T. Determination of the wavelength dependence of refractive indices of flame soot. Proc. R. Soc. A 1990, 430, 577-591. [CrossRef]

26. Zhou, K.; Jiang, J. Thermal Radiation from Vertical Turbulent Jet Flame: Line Source Model. J. Heat Transf. 2016, 138. [CrossRef]

27. Zhang, H.; Modest, M.F. Evaluation of the Planck-mean absorption coefficients from HITRAN and HITEMP databases. J. Quant. Spectrosc. Radiat. Transf. 2002, 73, 649-653. [CrossRef] 